\title{
Empirical Research on Regional Human Capital Carrying Capacity
}

\section{Zhixin Zhang and Fu Liang}

School of Business Administration Shandong University of Finance and Economics, Jinan 250014, China

zhangzhixin2020@163.com

\begin{abstract}
Keywords: Human Capital, Regional Human Capital Carrying Capacity, Principal Component Analysis.

Abstract. Based on the perspective of regional human capital carrying capacity, this study selects regional human capital carrying capacity evaluation indexes and uses the principal component analysis method to carry out factor analysis of relevant evaluation indexes, regional human capital carrying capacity evaluation indexes include: economic and social factors, innovation factors and environmental factors.
\end{abstract}

\section{Introduction}

As an important resource to promote the development of regional economy, the role of human capital has become increasingly prominent. Human capital is usually composed of knowledge, ability and technology quality which is condensed on the labor force and has economic value. It reflects the level of labor in a specific area. The high level of human capital is the key to the development of the society and the economy [1]. Human capital and material capital show complementary significantly [2], on the one hand, the material capitalis a carrier of human capital that play a role in the economic field, embody the human capital of the "soft power"; on the other hand, human capital increase the output elasticity of physical capital, alleviate the problem of diminishing marginal returns due to excessive physical capital [3].

From the above point of view, the rational allocation of human capital and material capital can play their respective utility. Any party's relative excess or shortage cannot achieve good economic output effect. In short, the common output of human capital and material capital depend on the proportions of the two parties. Human capital and material capital in different regions can take shape regional human capital capacity, Regional human capital capacity requires that the stock of human capital in the region should be proportional to the input of material capital, so as to effectively promote the development of regional economy. Therefore, based on the perspective of regional human capital capacity, this study selects the evaluation index of regional human capital carrying capacity, and uses principal component analysis to conduct the factor analysis of the relevant evaluation indicators, so as to complete the empirical research on the evaluation of regional human capital carrying capacity.

\section{The Connotation of Regional Human Capital Carrying Capacity}

Regional human capital carrying capacity refers to the human capital stock required to maximize the output efficiency of various production factors within a certain period of time. The essence is that the stock of human capital in the region should be proportional to the amount of material capital input. That at a certain time and space, a certain scale of human capital stock can support of social and economic development, the largest area of the differences of human capital and material capital investment proportion will form a significant difference in the human capital carrying capacity, thus affect the utilization rate of human capital. In general, the human capital carrying capacity, physical capital and institutional environment are closely related. On the one hand, regional human capital and material capital cannot entirely replace, a certain quantity and quality of the material capital is the premise and guarantee for human capital; On the other hand, the subjective initiative of the workers has a significant impact on the maximization of human capital's utility. Therefore, human capital is dependent on the restrictive effect of regional institutional environment. Therefore, human capital in 
the region cannot promote regional economic development alone, and must cooperate with material capital. At the same time, human capital is a kind of active capital, which is not a passive adaptation to material capital. It can be a carrier of material capital and realize their respective utility.

\section{The Selection of Human Capital Carrying Capacity Index}

The selection of human capital carrying capacity index should conform to the requirements of empirical research, ensure that the selection of indicators can fully reflect the essential characteristics of human capital carrying capacity. In this study, fourteen statistical indicators are selected to reflect the regional human capital carrying capacity, combined with the China statistical yearbook (2015) of the relevant statistical data to conduct reasonable empirical analysis, and includes the following regional human capital carrying capacity evaluation indicators: gross production, total retail sales of consumer goods, education expenditure, social security and employment expenditure, number of ordinary colleges and universities, new fixed assets, number of Internet users, medical and health expenditure, urban registered unemployment, science and technology expenditure, number of corporate units of foreign-invested enterprises, average selling price of residential housing, urban road area per capita and public green areas per capita.

\section{Regional Human Capital Carrying Capacity Empirical Analysis}

\subsection{Correlation Test}

The basic requirement of factor analysis is that the selected indicators have a certain degree of correlation. Therefore, this study used KMO value and Bartlett sphericity test to examine the correlation of statistical data. In this study, the above fourteen regional human capital carrying capacity evaluation indicators are tested by KMO and Bartlett sphericity. The results show that the $\mathrm{KMO}$ value is 0.819 and the Bartlett sphericity test card value is 678.053 , and reaches a significant level, as shown in table 1 . Therefore, there are public factors among the evaluation indexes of regional human capital carrying capacity which is suitable for factor analysis

Table1 KMO and Bartlett Sphericity Test

\begin{tabular}{l|c|c}
\hline \multicolumn{2}{|c|}{ KMO } & 0.819 \\
\hline \multirow{2}{*}{ Bartlett Sphericity Test } & Approximate Chi-square & 678.053 \\
\cline { 2 - 3 } & Df & 91 \\
\cline { 2 - 3 } & Sig. & .000 \\
\hline
\end{tabular}

\subsection{Determining Public Factors}

This study uses principal component analysis to determine the number of public factors. According to the conventional way of operation, we extract the factor with the characteristic value greater than 1 as a common factor to achieve the requirement of empirical analysis. It is known from table 2 that there are three factors with characteristic values greater than 1 , and their eigenvalues are 7.506 , 3.047and1.807, respectively. The explanatory power of variance are $53.617 \%, 21.765 \%$ and $12.904 \%$ and the ability to explain the cumulative variance are up to $88.286 \%>85 \%$. It can be seen that the three common factors extracted from this study carry fourteen original information of regional human capital carrying capacity evaluation index, which reduces the information loss of evaluation index to the lowest level, so as to achieve the requirement of empirical analysis.

Table 2 The Total Variance of the Explanation of Regional Human Capital Carrying Capacity Evaluation Index

\begin{tabular}{ccccccc}
\hline \multirow{2}{*}{ Common Factor } & \multicolumn{3}{c}{ Initial Eigenvalues } & \multicolumn{3}{c}{ Rotated Square Sum Loading } \\
\cline { 2 - 6 } & Sum Total & Variance $/ \%$ & Cumulative $/ \%$ & Sum Total & Variance /\% & Cumulative /\% \\
\hline 1 & 8.600 & 61.425 & 61.425 & 7.506 & 53.617 & 53.617 \\
2 & 2.246 & 16.046 & 77.471 & 3.047 & 21.765 & 75.382 \\
3 & 1.514 & 10.815 & 88.286 & 1.807 & 12.904 & 88.286 \\
\hline
\end{tabular}

\subsection{The Clustering and Interpretation of Public Factors}

The factor load matrix after rotation is obtained according to the calculation of the principal component load, as shown in table 3. Each factor in factor load matrix represents the correlation 
between each evaluation index and the extracted common factors. If the absolute value is large, then the evaluation index has strong correlation with the corresponding common factors. Results show that gross production, total retail sales of consumer goods, education expenditure, social security and employment expenditure, number of ordinary colleges and universities, new fixed assets, number of Internet users, medical and health expenditure, and urban registered unemployment are above 0.8 in the first public factor of load. Therefore, the first public factor has the strongest explanatory power to the above nine evaluation indicators, defining the first public factor as economic and social factors; science and technology expenditure, number of corporate units of foreign-invested enterprises, average selling price of residential housing are above 0.8 in the second public factor of load. Therefore, the second public factor has the strongest explanatory power to the above three evaluation indicators, defining the second public factor as innovation factors; urban road area per capita and public green areas per capita are above 0.8 in the third public factor of load. Therefore, the third public factor has the strongest explanatory power to the above twe evaluation indicators, defining the third public factor as environmental factors.

Table.3 Post Rotation Factor Load Matrix

\begin{tabular}{cccc}
\hline evaluation index & \multicolumn{3}{c}{ common factor } \\
\cline { 2 - 4 } gross production & 1 & 2 & 3 \\
\hline total retail sales of consumer goods & $\mathbf{0 . 8 3 8}$ & 0.450 & 0.267 \\
education expenditure & $\mathbf{0 . 8 5 2}$ & 0.436 & 0.230 \\
social security and employment expenditure & $\mathbf{0 . 8 7 5}$ & 0.377 & 0.181 \\
number of ordinary colleges and universities & $\mathbf{0 . 9 0 7}$ & 0.081 & -0.128 \\
new fixed assets & $\mathbf{0 . 9 4 3}$ & 0.171 & 0.020 \\
number of Internet users & $\mathbf{0 . 8 9 2}$ & -0.010 & 0.290 \\
medical and health expenditure & $\mathbf{0 . 8 7 7}$ & 0.339 & 0.178 \\
urban registered unemployment & $\mathbf{0 . 9 2 1}$ & 0.207 & 0.068 \\
science and technology expenditure & $\mathbf{0 . 9 0 2}$ & -0.116 & -0.155 \\
number of corporate units of & 0.482 & $\mathbf{0 . 8 1 9}$ & 0.126 \\
foreign-invested enterprises & 0.345 & $\mathbf{0 . 8 6 8}$ & 0.045 \\
average selling price of residential housing & -0.119 & $\mathbf{0 . 8 7 6}$ & -0.299 \\
urban road area per capita & 0.090 & -0.304 & $\mathbf{0 . 8 4 2}$ \\
public green areas per capita & 0.045 & 0.149 & $\mathbf{0 . 8 2 0}$ \\
\hline
\end{tabular}

Note: extraction method-principal component analysis; rotation method-orthogonal rotation with Kaiser standardization; convergence after 5 iterations.

\section{Summary}

Based on the perspective of regional human capital carrying capacity, this study determines and selects regional human capital carrying capacity evaluation indicators, taking the relevant statistical data of the National Statistical Yearbook in 2015, and uses principal component analysis to explore the related indicators. Evaluation indexes include: economic and social factors, innovation factors and environmental factors. This study is helpful to solve the problem of irrational allocation of human capital and material capital and to provide scientific reference coordinates for the realization of a good regional human capital carrying capacity.

\section{Acknowledgments}

Foundation item: Natural Science Foundation of Shandong Province (ZR2017MG003)

\section{References}

[1]. .Glaeser E L, Resseger M G. The Complementarity between Cities and Skill. Journal of Regional Science, vol.50 (2010) No. 1, p. 221-244. 
[2]. .Ciccone A, Papaioannou E. Human Capital, the Structure of Production, and Growth. Social Science Electronic Publishing, vol.91 (2009) No. 1, p. 66-82.

[3]. .Pablo-Romero M D P, Gomez-Calero M D L P. A translog production function for the Spanish provinces: Impact of the human and physical capital in economic growth. Economic Modelling, vol.32 (2013), p.77-87. 